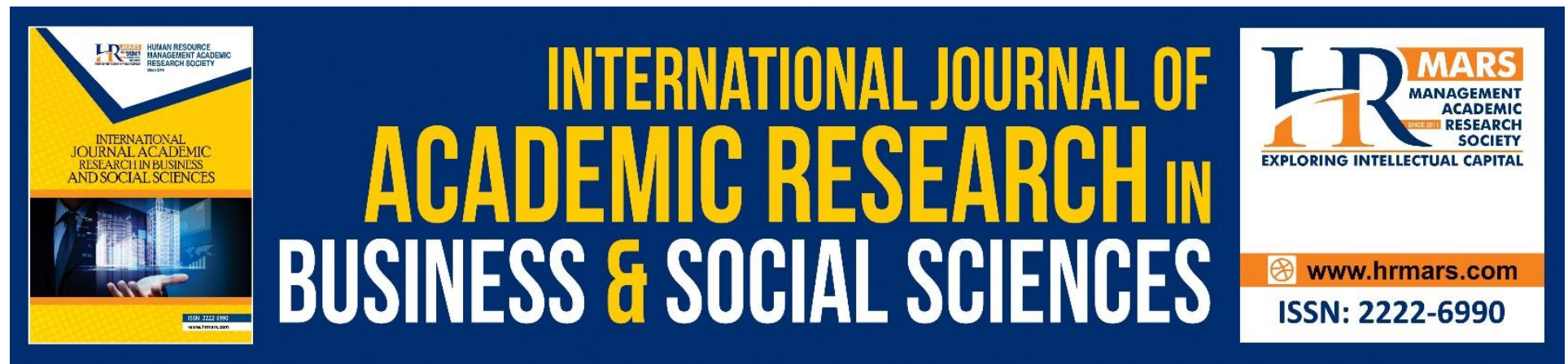

\title{
Injury Profile of Contact-Sports for Perak Athletes in Malaysia
}

\author{
Ai Choo Lee, Zou Chein Lee
}

To Link this Article: http://dx.doi.org/10.6007/IJARBSS/v8-i9/4672

DOI: $\quad 10.6007 /$ IJARBSS/v8-i9/4672

Received: 17 August 2018, Revised: 09 Sept 2018, Accepted: 29 Sept 2018

Published Online: 15 October 2018

In-Text Citation: (Lee \& Lee, 2018)

To Cite this Article: Lee, A. C., \& Lee, Z. C. (2018). Injury Profile of Contact-Sports for Perak Athletes in Malaysia. International Journal of Academic Research in Business and Social Sciences, 8(9), 965-976.

Copyright: @ 2018 The Author(s)

Published by Human Resource Management Academic Research Society (www.hrmars.com)

This article is published under the Creative Commons Attribution (CC BY 4.0) license. Anyone may reproduce, distribute, translate and create derivative works of this article (for both commercial and non-commercial purposes), subject to full attribution to the original publication and authors. The full terms of this license may be seen

at: http://creativecommons.org/licences/by/4.0/legalcode

Vol. 8, No. 9, September 2018, Pg. 965 - 976

http://hrmars.com/index.php/pages/detail/IJARBSS

JOURNAL HOMEPAGE

Full Terms \& Conditions of access and use can be found at http://hrmars.com/index.php/pages/detail/publication-ethics 


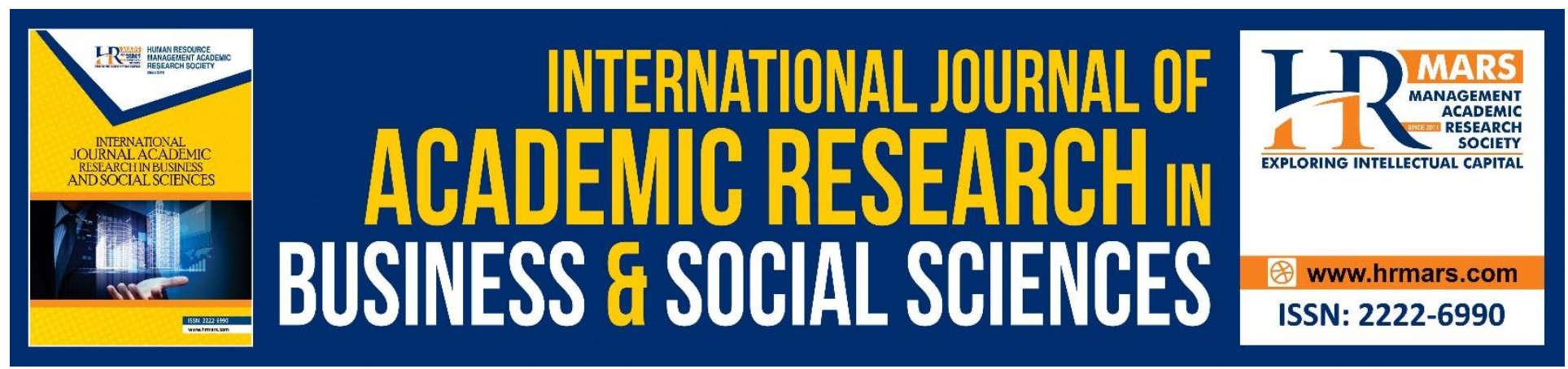

\title{
Injury Profile of Contact-Sports for Perak Athletes in Malaysia
}

\author{
${ }^{1}$ Ai Choo Lee, Phd., ${ }^{1}$ Zou Chein Lee \\ ${ }^{1}$ Faculty of Sport Science and Coaching, Sultan Idris Education University, Malaysia
}

\begin{abstract}
Numerous injuries occur each year caused by sports, resulting in decreased physical activity and work time lost in addition to substantial medical costs. Prevention and intervention have become focal points for researchers and clinicians. Due to the lack of evidence related to injury patterns among Perak athletes in Malaysia for entire contact-sports, risks of injury cannot truly been identified. Thus, the purpose of this study is to identify the injury profile of contact-sports for Perak athletes, and to determine the injuries pattern among the athletes. In the same time, suggesting injury prevention strategies in order to reduce the risks of injury. Descriptive research design is utilized in this study. There were 533 Perak athletes from seven contact-sports i.e hockey, judo, karate, taekwondo, silat, tinju and wushu participated in this study. There were 105 athletes who reported injured were recruited and completed the self-administered questionnaire. The data is examined based on the research questions: a) common types of injuries, b) common body locations of injuries and c) common risk factors of injuries. The descriptive statistics i.e. frequency and percentage were utilized to analyze the research variables. The study findings indicated that muscles cramp, sprain and strain were the most common types of injuries. The reflection of intensity of physical interactions involved in the sporting activities becomes the common causes of different types of injuries. While lower extremities i.e ankle, knee and thigh became the common body locations of injuries. Opponent was found as major risk factor to injury. This study suggesting that the injury prevention strategies should focus on proper stretching during warm-up, ensure the training volume, proper landing techniques, ensure the injured athletes receive adequate rehabilitation, implementation of injury prevention programming, rules changes and emphasize on effective equipment. In conclusion, this injury profile is able to provide sufficient information in reducing and preventing injury occurrence thus helps maintaining athlete's health at optimum level.
\end{abstract}

Keyword: Injury Profile, Contact Sports, Lower Extremities, Injury Prevention Strategies.

\section{Introduction}

In recent year, the sport has become famous throughout the country but this phenomenon causes the more injury risk to be exposed to the athletes. Participation in sport provides health, 
social benefit, and causes an innate risk of injury exists. An athlete's performance will veil if they suffer in the injury as well as his/her movement will be limited. The trauma, pain and loss of function accompanying injury can be substantially detrimental to the participant, by preventing sports participation or negatively affecting performance. In the addition, numerous injuries occur each year caused by sports, resulting in decreased physical activity and work time lost in addition to substantial medical costs. Worldwide, the cost of sports injuries has been estimated at $\$ 1$ billion annually. Kraus and Conroy (1984) estimated that 3-5 million injuries occurred annually among competitive and recreational athletes in the United States alone. Musculoskeletal injuries in sports are a common yet unwanted aspect of participation in sports. Although, sports injuries cannot be entirely eliminated, consistent and professional evaluation of the pattern can provide a focus for the development of injury prevention strategies. However, the occurrence and magnitude of the effects of many injuries may be reduced with the implementation of injury prevention strategies. Perak Sports State Council in Malaysia has the vision to improve high performance activities from the grassroots level to elite level. Mission is to make Perak state a main producer of national athletes and place the state at the highest level of excellence with true sporting spirit and be a sports powerhouse to be reckoned with in Malaysia by improve sport by provide adequate facilities and regulating the State Sports Association and Sports agencies in order to improve Perak athletic performance. Thus, prevention and intervention have become focal points for researchers and clinicians. Perak state sports experts, strength and conditioning coach, physiotherapist, sports nutritionist, sports massage therapist and applied exercise physiologist have to aware of the risk factors that cause injury in sports, particularly in contactsports. The data is beneficial to athletes and the coaches to realize what are the injury risk factors to help in injury prevention. It is important to help sports medicine team to design injury prevention program. The aim of this study is to determine the prevalence of injury pattern in contact-sports for Perak athletes in Malaysia.

\section{Purpose of the Study}

The amount of published epidemiological studies in entire contact-sports is small compare to specific single contact-sports. Due to the lack of evidence related to injury patterns among Perak athletes in Malaysia for entire contact-sports, a problem of risks of injury in various contactsports cannot truly been identified. Thus, the aim of this study is to determine the prevalence of injury pattern in contact-sports for Perak athletes in Perak Sports State Council, Malaysia. The specific objectives of this study are as below: (1) to determine the most common types of injuries, (2) identify the most common body locations of injuries and (3) identify the most common risk factors of injuries in contact-sports for Perak athletes in Malaysia. In the same time, suggesting injury prevention strategies in order to reduce injury occurrence.

\section{Literature Review}

Injuries are common within athlete population, with high incidence rates well established in the literature. Injuries cause a substantial number of training days lost, a significant cost through compensation claims and an increased risk of attrition. In an effort to address this, a considerable amount of research has gone into identifying the most prevalent types of injury and their associated risk factors. (Andersen et al., 2016) Prevention and intervention have become focal 
points for researchers and clinicians. The risk factors for injury must be clearly established before designing prevention program and intervention (Murphy et al., 2003).

The research of Theisen et al., (2012) found that the incidence of both traumatic and overuse injuries are high. Ayanniyi et al., (2015) stated that strain is reported as most common type of injury among soccer players ( $n=15,46.9 \%)$ while sprain was reported to be predominant among basketball players ( $n=20,62.5 \%$ ). In addition, Connor et al., (2015) found that hamstring injuries were more frequent in footballers (13.3\%).

Connor et al., (2016) stated that lower limb injuries were predominant with a similar rate noted in adolescent Gaelic footballers as the $70-77 \%$ reported in adult players. Besides that, Scase et al., (2012), stated that the common body location of injuries was lower limb $(n=164,72.2 \%)$, hip/groin/thigh $(n=8,35.2 \%)$, shin/ankle/foot $(n=54,23.7 \%)$ and knee $(n=30,13.2 \%)$. The researchers stated that the category "ankle joint injuries" was the most commonly reported $(n=34)$. Ayanniyi et al., (2015) stated that the region of lower limb from the groin to the foot was the most injured body part among soccer players accounting for $74.4 \%$ of the total injuries.

Scase et al., (2012) reported that "collision with another player" was the main injury mechanism $(n=75)$. It concluded that the most commonly injured region in junior elite

Australian Football was ankle and collision with another player was the most common injury mechanism. Besides that, Ayanniyi et al., (2015) stated that tackling from opposing players as the major cause of injury among soccer players $(n=13,40.6 \%)$. The most common mechanisms of injury were player to player contact $(42.8 \%)$, no contact $(37.9 \%)$ and player to surface contact (13.6\%). In the addition, Dick et al., (2007) reported that player contact and other contact (e.g. ball, blocking dummies, ground) is highest injury mechanism of football injuries.

\section{Methodology}

Descriptive study design is utilized in this study. A descriptive study design is one in which the primary goal is to assess a sample at one specific point in time without trying to make inferences or causal statements. In general, there are three primary reasons to conduct descriptive studies, to identify areas for further research, help in planning resource allocation, providing informal information about a condition. This research design used to verify the current injury profile of contact-sports among athletes in Perak Sports State Council, Malaysia to review types of injury, body location of injury and risk factors of injury between various contact-sports.

The population of the study was 533 athletes who representing Perak state for all seven contactsports such as hockey, judo, karate, silat, tinju, wushu and taekwondo were involved in this study. The convenience sampling method was utilized. All eligible injured athletes were screened based on study inclusion criteria listed i.e (1) athletes involve in contact-sports, (2) athletes that representing Perak state for a year or more and (3) athletes that injured after involve in games representing Perak. Meanwhile, exclusive criteria of the study were (1) unclear of injury history, (2) previous injury occurred before representing Perak team and (3) athletes who representing 
Perak team less than a year. After screening process, 105 athletes were recruited and agreed to participated in this study (Refer Table 3.3).

The research instrument used in this study was a self-administered questionnaire. The questionnaire is divided into two parts. Part I is including background information and personal information such as athlete's gender, age, type of sports involved, period participate and the age of initial exposure, period of participate, level of the sports. Part II is regarding the injuries profiles such as types of injury, body location of injury and the risks factors that cause the injury among the Perak athletes in Perak Sports State Council.

To ensure data was collected precisely according to research needs, a data collection form was designed. In order to find out the instrument reliability, a pilot study was conducted. The instrument reliability is analyzed using Interclass Correlation Coefficient (ICC). The Interclass Correlation Coefficient revealed ICC $=0.84$ indicating that the instrument i.e. injuries questionnaire used in this study obtained good level of reliability (Shrout and Fleiss, 1979).

The questionnaires were distributed to the athletes during training session or rehabilitation session after giving consent. All athletes answered questionnaires about demographic data (i.e. gender, age, type of sports involved, period participate and the age of initial exposure, period of participate, level of the sports) and injuries profile (type of injury, body location of injury and the risks factors that cause the injury following various sports played by athletes). They were given 20 minutes to complete the questionnaire. The questionnaires were collected on the same day. Questions from the athletes with respect to understanding of the questionnaire were allowed and answered. The rationale and procedure for the study were explained to all available athletes and their consent to participate in the study was obtained and sought. All injury cases documented as single case following data collection form. If there is an athlete who has multiple types of injury in same body location or injured on multiple body parts, in these cases were count as one sample data. The data was no valid and considerate as a drop out case if the sample data do not meet the criteria in the data collection. If only the data collection form is completed, it counted as a valid case.

\section{Data}

A descriptive statistic with cross tabulation was used to show a meaningful frequency and percentage distributions in process of analyzing all three research questions. The data was analysed by descriptive statistic using Statistical Package for Social Sciences 20.0 (SPSS). The significant level of this study was predetermined at $p<0.05$.

\section{Results}

Table 1 displayed the frequency and percentage distributions of common types of injury in contact-sports for Perak athletes in Malaysia. The results showed that muscle cramp as the most common types of injuries (25.4\%) followed by sprains (16.5\%), strains (15.3\%), abrasion (14.4), laceration $(12.3 \%)$, fracture $(5.9 \%)$, tendon strain $(3.4 \%)$, dislocation $(2.1 \%)$, shin splint $(2,1 \%)$, tendonitis $(0.85 \%)$, bursitis $(0.85 \%)$, nerve injury $(0.42 \%)$ and contusion $(0.42 \%)$. 
Table 1: Frequency and Percentage Distribution on Common Type of Injury among Perak Athletes in Contact-Sports

\begin{tabular}{|c|c|c|c|}
\hline Q1 & Variables & $f$ & $\%$ \\
\hline \multirow{4}{*}{ Types of injuries } & Muscle cramp & 60 & 25.4 \\
\cline { 2 - 4 } & Sprain & 39 & 16.9 \\
\cline { 2 - 4 } & Strain & 36 & 15.3 \\
\cline { 2 - 4 } & Abrasion & 34 & 14.4 \\
\cline { 2 - 4 } & Laceration & 29 & 12.3 \\
\cline { 2 - 4 } & Tendon strain & 8 & 3.4 \\
\cline { 2 - 4 } & Dislocation & 5 & 2.1 \\
\cline { 2 - 4 } & Shin splint & 5 & 2.1 \\
\cline { 2 - 4 } & Tendonitis & 2 & 0.85 \\
\cline { 2 - 4 } & Bursitis & 2 & 0.85 \\
\cline { 2 - 4 } & Nerve injury & 1 & 0.42 \\
\cline { 2 - 4 } & Contusion & 1 & 0.42 \\
\hline
\end{tabular}

Figure 1 revealed the types of injuries among Perak athletes in contact-sports. The result showed that muscle cramp (25.4\%) is the most common injuries by sprain (16.9\%) and strain (15.3\%). Contusion $(0.42 \%)$ and nerve injury $(0.42 \%)$ were reported as least common injuries (Refer to Figure 1).

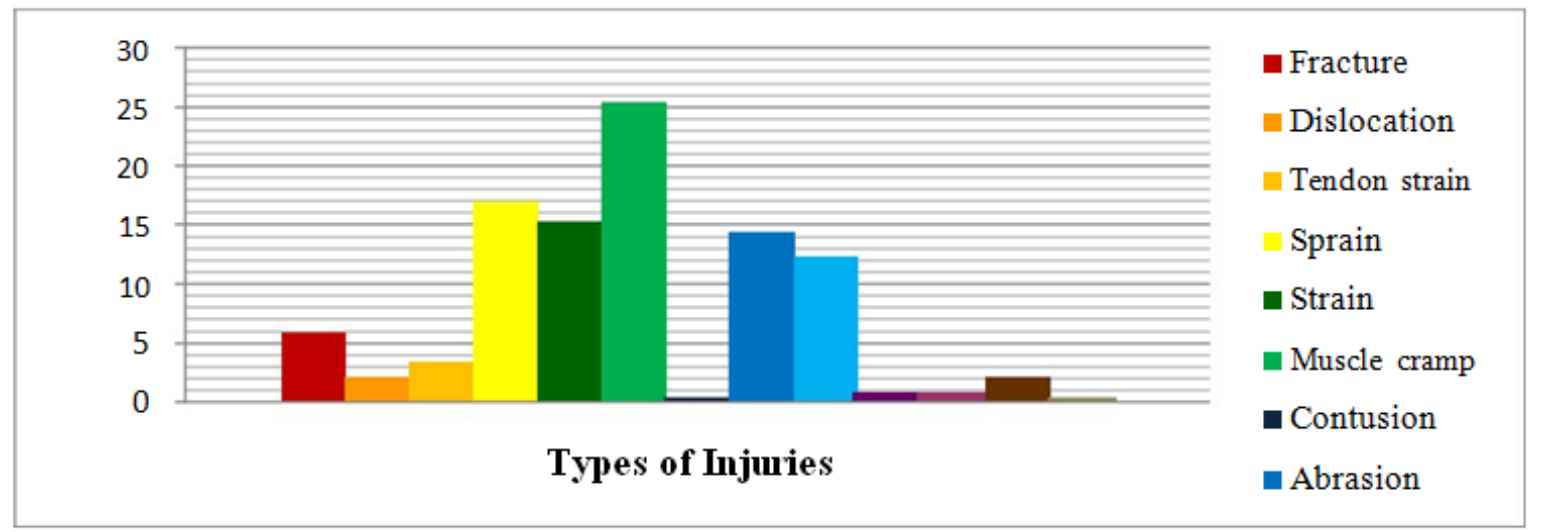

Figure 1: Percentage Distributions on Common Types of Injuries among Perak Athletes in ContactSports

Table 2 was tabulated to indicate the frequency and percentage distributions of common body locations of injuries in contact-sports for Perak athletes. The results showed that most injuries happened on lower extremities (66.8\%) compared to upper extremities (33.2\%). 
Table 2: Frequency and Percentage Distribution of Common Body Locations of Injuries among Perak Athletes in Contact- Sports

\begin{tabular}{|c|c|c|c|}
\hline Q2 & Variables & $f$ & $\%$ \\
\hline \begin{tabular}{c} 
Body locations of $\begin{array}{c}\text { injuries } \\
\text { injur| }\end{array}$ \\
\cline { 2 - 4 }
\end{tabular} & Lower extremities & 443 & 66.5 \\
\hline \multicolumn{2}{|c|}{ Total } & 223 & 33.5 \\
\hline
\end{tabular}

Figure 2 revealed that the percentage on common body locations of injuries among Perak Athlete in contact-sports. The result showed that lower extremities (66.5\%) is common body locations of injuries compared to upper extremities (33.5\%) (Refer to Figure 2).

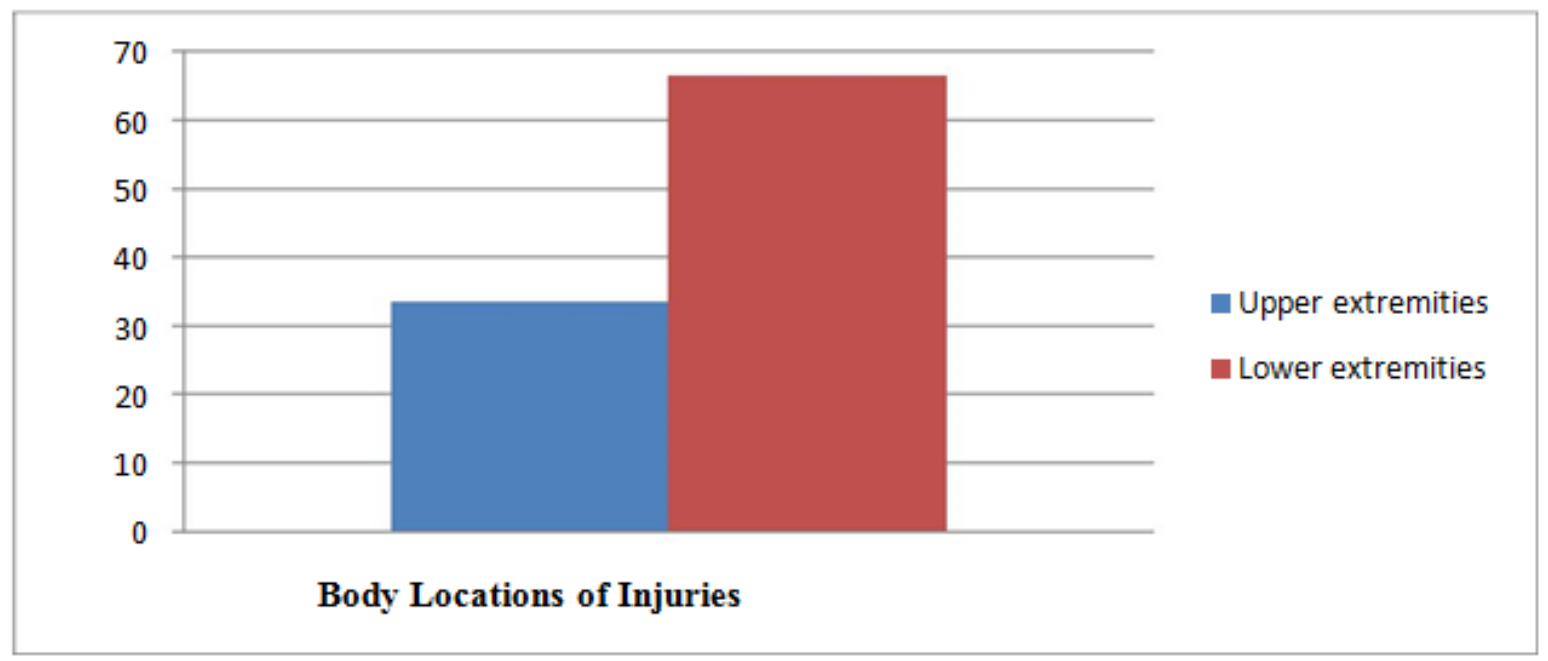

Figure 2: Percentage Distributions on Common Body Locations of Injuries among Perak Athletes in Contact-Sports

Table 3 revealed the frequency and percentage distributions of common risk factors of injuries in contact-sports for Perak athletes. The results indicated that opponent is the major risk factors that caused injuries to Perak athlete followed by self-induced, previous injury, equipment and environment.

Table 3: Frequency and Percentage Distribution of Common Risk Factors of Injuries among Perak Athletes in Contact- sports

\begin{tabular}{|c|c|c|c|}
\hline Q3 & Variables & $f$ & $\%$ \\
\hline \multirow{3}{*}{$\begin{array}{c}\text { Risk factors of } \\
\text { injuries }\end{array}$} & Opponent & 63 & 30.6 \\
\cline { 2 - 4 } & Self-induced & 50 & 24.3 \\
\cline { 2 - 4 } & Previous injury & 36 & 17.5 \\
\cline { 2 - 4 } & Equipment & 28 & 13.6 \\
\cline { 2 - 4 } & Environment & 27 & 13.1 \\
\cline { 2 - 4 } & Clothing & 2 & 0.97 \\
\hline \multicolumn{2}{|c|}{ Total } & 206 & 100 \\
\hline
\end{tabular}


Figure 3 showed the percentage distribution on common risk factors of injuries among Perak athletes in contact-sports. The results showed that opponent $(30.6 \%)$ is the most common risk factors followed by self-induced (24.3\%), previous injury (17.5\%), equipment (13.6\%) and environment (13.1\%) (Refer to Figure 3).

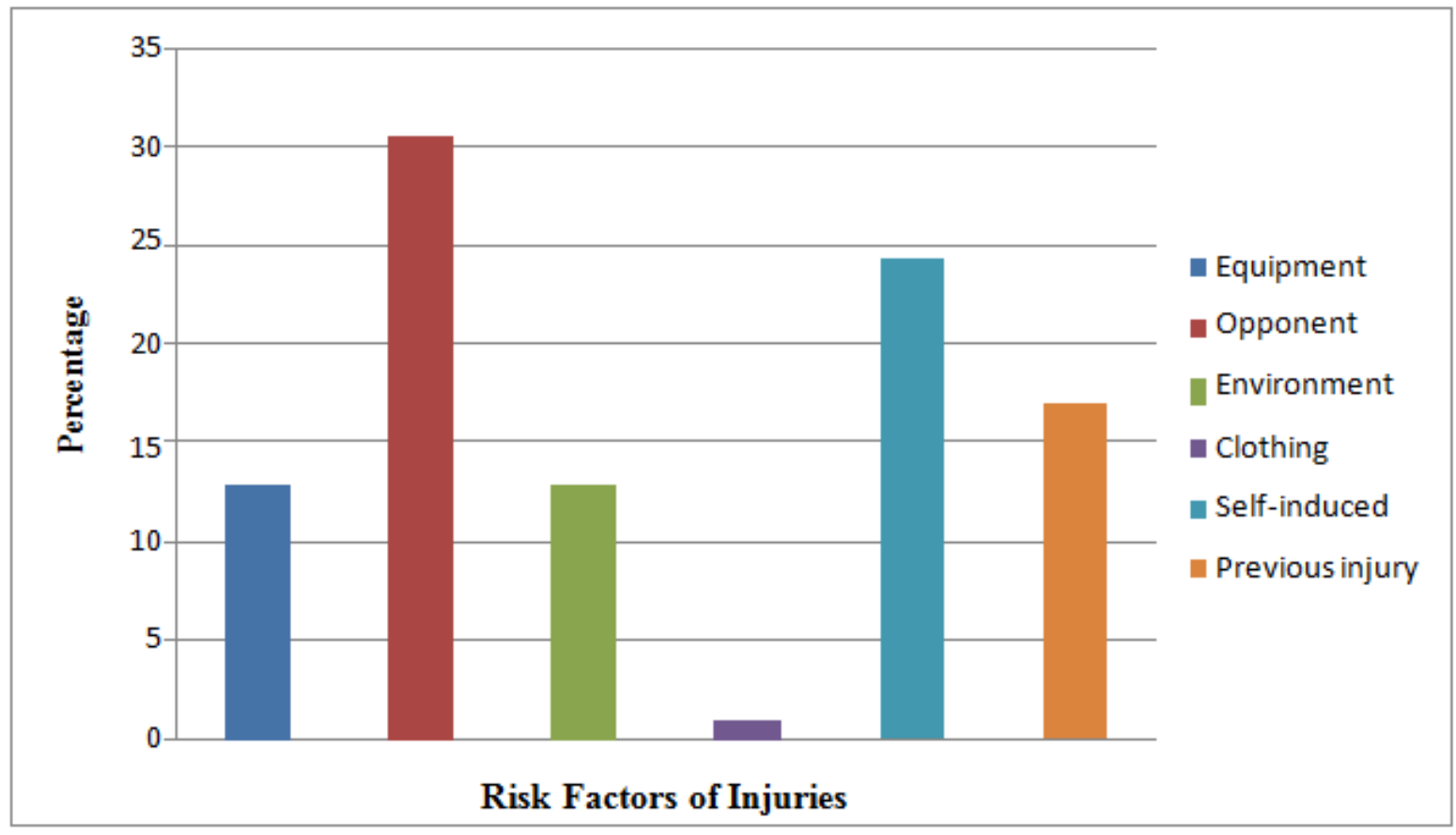

Figure 3: Percentage Distributions on Common Factors of Injuries among Perak Athletes in Contact-sports

\section{Discussion}

The application of this study is to provide information about characterization of sport injuries occurrence and risk factors among Perak athletes in Malaysia for contact-sports. The first research question in this study is to determine the common types of injuries in contactsports. Study results indicated that muscle cramp (25.4\%) is most common types of injuries, followed by sprain (16.9\%) and strain (15.3\%) compared to others type of injury. As Kerr et, al.,(2017) mentioned, may be the reflection of intensity of physical interactions involved in the sporting activities becoming the common causes of different types of injuries. The players evolve in a dynamic and rapidly changing environment, in which the high frequency of jumping, sprinting and pivoting may generate high strains and sprains on soft tissues. This can be explained by Wong at al., 2005, stated that during running and twisting and turning, uneven playing surfaces may result in more loading on the ligaments and muscles. When external loading is greater than the ligaments and muscles level of tolerate, injury usually follows. During running and twisting and turning, the main causes of injury are inferior playing surfaces and inappropriate footwear. Uneven playing surfaces may result in more loading on the ligaments and muscles. Injuries often happen during jumping and landing due to inappropriate footwear which cannot provide sufficient frictional force will eventually lead to slipping or incorrect landing technique. The prevention of these injuries should include stretching during warm up. The proper techniques of warm up before sports and cooling 
down after sports should be monitored closely by the coaches and athletes. Besides that, coaches have the responsible to ensure the athletes never over-exercising and in a state of exhaustion. The injury prevention strategies such as tracking training load, ensuring appropriate biomechanics, sufficient rehabilitation post-injury and education to players and coaches regarding the negative effects of playing through injuries to reduce the risk of overuse injuries are required. Besides that, medical team should ensure the injured athletes receive adequate rehabilitation to return to play in order to avoid the athletes return to play without fully recovered from injury.

The study finding revealed that most common injury location among Perak athletes in contact-sports was lower extremities (66.5\%) followed by upper extremities (33.5\%). This is supported by Lee et al., (2017) stated that lower extremities (51.1\%) seems to be the most common injury location in non-contact sports. Study finding indicated that high incidence of ankle and knee injuries in contact-sports among Perak athletes. A possible reason for the vulnerability of the ankle to injury is its close proximity to the contact surface (eg. equipment and opponent's body), which is the focus of activity in the contact-sports. Besides that, previous study by Ayanniyi et al., (2015) suggested that ankle adjudged as one of the most vulnerable part of the body that contact-sports players usually sustain injuries. Therefore, the chances of ankle injury in contact-sports are highest when dribbling, shooting, kicking, and tackling. However, Connor et al., (2016) had suggested that knee injuries were common could be caused by poor neuromuscular control at the knee. It also may be due the large pressure and force undertaken by the knee when performing kicking movement. Hawkins et al., (1998) suggested that the knee is very susceptible to injury from large forces produced by kicking opponent to score. Thigh injuries, hamstring injuries or upper leg injuries also one of the common body locations of injuries among Perak athletes in contact-sports. One of the contact-sports in this study, hockey becoming more of "a running game" with players using a series of short passes that require them to cover longer overall distances which may cause the muscle cramp due to the overuse of hamstring in the game or training. Continued development and implementation of injury prevention programming and ankle bracing, taping and strengthening is necessary to further reduce risk of injury, particularly related to lower extremities. Traditional ankle taping or semi rigid bracing of the ankle may decrease the rate of persistent ankle sprains (Kaminski et al., 2013). By teaching the preventative exercise programs such as proper landing and take-off techniques, knee sprains can be decreased. In the addition, neuromuscular training program should be emphases to the athletes to improve their proprioceptive function and stability of the joint at lower limbs to lower the risk of injuries on lower limb.

Opponent seems to be the main risk factor that causes injuries in contact-sports among Perak athletes in Malaysia. Most of the injuries happened during contact-sports were due to hit or collision from the opponent and equipment of opponent. As what can be determined from the data that most of the injuries happened in contact-sports are acute injury that mainly contribute from unpredictable movement and incidence. The most common injury mechanisms were tackling, running, being tackled, shooting, twisting and turning, and jumping and landing. Higher contact injury rates may due to collision or tackled by players 
with faster speed. It is likely that well-developed speed permits greater playing performance through the development of greater impact forces in tackles. However, perhaps not surprisingly, the greater impact forces generated from the development of this physical quality also appears to result in an increase in contact injury rates. On the other hand, risk factors of injuries in martial art such as taekwondo, karate, wushu, silat, judo and tinju have higher risk factors in contact with opponent.

This is probably explained by the difference in contact. For example, the emphasis in taekwondo is on fast, powerful kicks, which have the potential for causing severe injury. The potential decrease may be associated with equipment and rule changes that aimed to increase athlete safety and health. Helmet face mask, shoulder pads, flak jackets and others padding garments should be improved in technological aspect to improve to protection from contact injuries. The enhanced force dissipation and the materials used in the equipment may aid in the reduction of force transmitted to the body. In the addition, rule changes or rules emphasis may directly pertain to contact injuries, body checks or hits the head since then. Current competition rules should be re-evaluate that allow blows to the head/face to help reduce injuries that recommended limiting the amount of contact that occurs during the game. New rule should integrated making it illegal to use a body part to initiate contact with an opponent's body. Besides that, proper checking skills in hockey sport should be ensuring and reinforcing to mitigate injury risk. Such detail will help to identify specific areas of game play where injury prevention can be focused (Kerr et al., 2017).

\section{Recommendation of the Study}

For future research, it was suggested to expand such study to all states in Malaysia for contact and non-contact sports so that each state is awared of their athletes injury profile, thus providing useful information in order to overcome the threat of injury among athletes.

\section{Conclusion}

The study is demonstrated the significance of the effective injury surveillance system using epidemiological data in monitoring of athlete's health. Due to the important of the future injury preventative strategies, this information is important for sports authorities to identify athletes who are at risk of sports injury. The effort to provide appropriate rehabilitation and preventive strategies could help to reduce injuries and maintaining athlete's health at optimum level, thus, providing greater sports performance. In the same time, it helps reducing government health cost on preventable injury. 
INTERNATIONAL JOURNAL OF ACADEMIC RESEARCH IN BUSINESS AND SOCIAL SCIENCES

Vol. 8, No. 9, Sept. 2018, E-ISSN: 2222-6990 (C) 2018 HRMARS

\section{References}

Anderson K.A., Grimshaw P. N., Kelson R. M. \& Bentley D. J. (2016). Musculoskeletal lower limb injury risk in army populations. Sport Med Open, 2(22), 1-9.

Arendt E. A., Agel, J., \& Dick, R. (1999). Anterior cruciate ligament injury patterns among collegiate men and women. Jornal of Athletic Training, 34 (2), 86-92.

Ayanniyi O., Abiodun O.\& Adekanla B. A. (2015). Pattern of musculoskeletal injuries among soccer and basketball players in a Nigerian university. Journal of the Romanian Sports Medicine Society, 11(4), 2676-2681.

Connor S.O., McCaffrey N. \& Whyte E. F. (2016). Epidemiology of injury in male adolescent gaelic games. Journal of Science and Medicine in Sport, 19, 384-388.

Dick, R., Ferrara, M., Agel J. Courson, R., Marshall S. W., Hanley M. J. \& Geifsteck F. (2007). Descriptive epidemiology of collegiate men's football injuries. Journal of Athletic Training, 42(2), 221-233.

Engebretsen L., Soligard T., Steffen K., Alonson J. M., Aubey M., Budgett R., Dvorak J., Jegathesan M., Meeuwisse W. H., Mountjoy M., Palmer-Green D, Vanhegan I. \& Renstorm P. A.(2013). Sports injuries and illnesses during the London Summer Olympic Games 2012. Br J Sports Med, 47, 407-414.

Kaminski T. W., Fayson S. D. \& Needle A. R. (2013). The effects of ankle kinesio taping on ankle stiffness and dynamic balance. Research in Sports Medicine, 21, 204-216.

Kraus J. F. \& Conroy C. (1984). Mortality and morbidity from injuries in sports and recreation. Annu Rev Public Health. 5, 163-192.

Hawkins R. D \& Fuller C. W. (1998). An examination of the frequency and severity of injuries and incidents at three levels of professional football. Br J Sports Med, 32, 326-332.

Hootman J. M. \& Dick R., Agel J. (2007). Epidemiology of collegiate injuries for 15 sports. Journal of Athletic Training, 42(2), 311-319.

Joseph, A. M., Collins C. L., M., Henke N. M., B., Yard E. E., Fields S. K. \& Comstock R. D. (2013). A multisport epidemiologic comparison of anterior cruciate ligament injuries in high school athletics. Nata Journal, 48(6), 810-817.

Kerr Z. Y., Quigley A., Yeargin S. W., Lincoln A. E., Mensch J., Caswell S. V \& Domier T. P. (2017). The epidemiology of NCAA men's lacrosse. Injury Epidemiology, 4(6), 1-11. 
INTERNATIONAL JOURNAL OF ACADEMIC RESEARCH IN BUSINESS AND SOCIAL SCIENCES

Vol. 8, No. 9, Sept. 2018, E-ISSN: 2222-6990 (C) 2018 HRMARS

Lee, A.C., Sankaravel, M., Mondam, S., Kuang, P.F. (2017). Injury profile of non- contact for Perak SUKMA athletes. Journal of Fundamental and Applied Sciences, 9 (6S), 1141-1151.

Malisoux L., Frish A.,Urhausen A. (2013). Monitoring of sport participation and injury risk in young athletes. Journal of science and medicine in Sport, 16(6), 504-508.

Malisoux L., Frish A., Urhausen A., Seil R. \& Theisen D. (2013). Injury risk is different in team and individual youth sports. Journal of Sciences and Medicine in Sports, 16 (6), 504-508.

Murphy D. F., Connolly D. A. J. \& Beynnon B. D. (2017). Risk factors for lower extremity injury. Br J Sports Med, 37, 13-29.

Oller D. M., Buckey W.E., P. M., Sebastiana W. E., J., M. \& Vairo G. L., (2015). Injury and illness epidemiology at a summer sport camp program, 2008 through 2011. Journal of Athletic Training, 50 (3), 313-320.

Palmer-Green D. \& Elliot N. (2015). Sports injury and illness epidemiology. Br J Sports Med, 49, 2529.

Pieter W. (2005). Martial arts injuries. Epidemiology of Pediatric Sports Injuries, 48, 59-73.

Scase E., Magarey M. E., Chalmers S., Heynen M., Petkov J. \& Bailey S. (2012). The epidemiology of injury for an elite junior Australian football cohort. Journal of Sciences and Medicine in Sport, 15(3) 207-212.

Shrout P. E. \& Fleiss J. L. (1979). Intraclass correlations : uses in assessing rater reliability. Psychological Bulletia, 86(2), 420-428.

Theisen D., Frish A., Malisoux L., Croisier J. \& Seil R. (2012). Injury risk is different in team and individual youth sports. Journal of Sciences and Medicine in Sports, 16(3), 200-204.

Tommasone B. A., Tamara C. \& Mcleod V. (2006). Contact sport concussion incidence. Journal of Athletic Training, 41(4), 470-472.

Wong P. \& Hong Y. (2005). Soccer injury in the lower extremities. Br J Sports Med, 39, 473-483.

Zetaruk M. N., Violan M., Zurakowski D.\& Micheli L. J. (2005). Injuries in martial arts: a comparison of five styles. Br J Sports Med, 39, 29-33. 